\title{
Assessing issues associated with a time-integrated fluvial fine sediment sampler
}

\author{
Masoud Goharrokhi ${ }^{1}$ (D) | Hoda Pahlavan ${ }^{2}$ | David A. Lobb ${ }^{1}$ | Philip N. Owens ${ }^{3}$ | \\ Shawn P. Clark ${ }^{2}$
}

${ }^{1}$ Department of Soil Science, University of Manitoba, Winnipeg, Manitoba, Canada

${ }^{2}$ Department of Civil Engineering, University of Manitoba, Winnipeg, Manitoba, Canada

${ }^{3}$ Environmental Science Program and Quesnel River Research Centre, University of Northern British Columbia, Prince George, British

Columbia, Canada

\section{Correspondence}

Masoud Goharrokhi, Department of Soil Science, University of Manitoba, 13 Freedman Crescent, Winnipeg, Manitoba R3T 2N2, Canada.

Email: umgoharr@myumanitoba.ca

Funding information

Natural Science and Engineering Research Council of Canada (NSERC) CREATE H2O; NSERC CRD BaySys, and NSERC Discovery (DAL)

\begin{abstract}
Collecting a representative time-integrated sample of fluvial fine-grained suspended sediment $(<63 \mu \mathrm{m})$ is an important requirement for the understanding of environmental, geomorphological, and hydrological processes operating within watersheds. This study (a) characterized the hydrodynamic behaviour of a commonly used timeintegrated fine sediment sampler (TIFSS) using an acoustic Doppler velocimeter (ADV) in controlled laboratory conditions and (b) measured the mass collection efficiency (MCE) of the sampler by an acoustic Doppler current profiler under field conditions. The laboratory results indicated that the hydrodynamic evaluations associated with the original development of the TIFSS involved an underestimation of the inlet flow velocity of the sampler that results in a significant overestimation of the theoretical MCE. The ADV data illustrated that the ratio of the inlet flow velocity of the sampler to the ambient velocity was $87 \%$ and consequently, it can be assumed that a representative sample of the ambient fine suspended particles entered into the sampler. The field results showed that the particle size distribution of the sediment collected by the TIFSS was statistically similar to that for the ambient sediment in the Red River, Manitoba, Canada. The MCE of the TIFSS in the field trials appeared to be as low as $10 \%$. Collecting a representative sample in the field was consistent with the previous findings that the TIFSS is a suitable sampler for the collection of a representative sample of sufficient mass (e.g., >1 g) for the investigation of the properties of fluvial fine-grained suspended sediment. Hydrodynamic evaluation of the TIFSS under a wider range of hydraulic conditions is suggested to assess the performance of the sampler during high run-off events.

\section{KEYWORDS}

fine sediment sampler, fluvial suspended sediment, mass collection efficiency, particle size

\section{1 | INTRODUCTION}

Studying fluvial fine-grained suspended sediment $(<63 \mu \mathrm{m})$ provides an understanding of the environmental, geomorphological, and hydrological processes operating within watersheds. Fine inorganic sediment behaves differently than coarser sediment mostly due to its characteristics such as weight, density, specific surface area, and electrical charge distribution. Lighter fine-grained sediment requires less flow energy for transportation in suspension and thus is transported further downstream, often reaching the coastal zone, whereas heavy, coarse-grained inorganic sediment moves more slowly, typically near the bottom of rivers (Walling, 2013). The high surface area (up to 
$>100 \mathrm{~m}^{2} \mathrm{~g}^{-1}$ ) and electrical charge distribution of fine inorganic suspended sediment are key factors for both flocculation (Droppo, 2001) and the binding of trace elements, organic matter, nutrients, and contaminants that are subsequently transported within rivers (Walling, Owens, Waterfall, Leeks, \& Wass, 2000). The properties of fine-grained sediment can also provide information on (a) the relative contribution of the source of sediment (i.e., sediment source fingerprinting; Owens et al., 2016; Walling, 2013) and (b) the impact of climate change and anthropogenic activities (e.g., changing land use, gravel mining, and dam construction) on watershed processes (e.g., Foster \& Lees, 1999; Kondolf et al., 2018). Fine suspended sediments are, therefore, suitable gauges of physical and biogeochemical processes in watersheds (e.g., erosion), as well as useful indicators of nutrient and contaminant conditions in aquatic ecosystems (Owens et al., 2005).

Given the highly sporadic nature of fine sediment transport dynamics in rivers, an ideal sampling method is presumably capable of collecting $100 \%$ of the sediment that enters the sampler continuously over a suitable time period (i.e., high-flow event, season, or year) and from the entire river cross section (i.e., depth and width integrated). Because this ideal sampling method is not practical, different samplers have been developed to collect a representative sample of the ambient fluvial fine suspended sediment. Phillips, Russell, and Walling (2000) developed an affordable and easily fabricated timeintegrated fine sediment sampler (TIFSS) for use in small (first and second order) streams of lowland areas where velocities are expected to be low (i.e., $<1 \mathrm{~m} \mathrm{~s}^{-1}$ ) with little to no maintenance requirements. This device collects temporally integrated samples from one point in a cross section. The original aim of the TIFSS was to obtain substantial quantities (e.g., $\geq 10 \mathrm{~g}$ ) of fine sediment over either a single (e.g., freshet) or a combination (e.g., rainfall) of events, in the absence of a power source. Typically, this apparatus is composed of an inlet $(4 \mathrm{~mm}$ [ID] $\times 15 \mathrm{~cm}$ ), an outlet tube (4 mm [ID]), and a polyvinylchloride chamber (98 mm [ID] × $100 \mathrm{~cm}$; Figure 1).

The TIFSS is installed horizontally in the river at $~ 60 \%$ of average depth with the inlet tube facing into the flow. Once the TIFSS is installed in the stream, water passes through the inlet tube at a velocity similar to the ambient flow velocity. The main chamber of the TIFSS decreases the water flow velocity by a factor in excess of 600 relative to the inlet tube flow velocity. Sedimentation of the fine sediment particles occurs as the water passes through the chamber and exits the

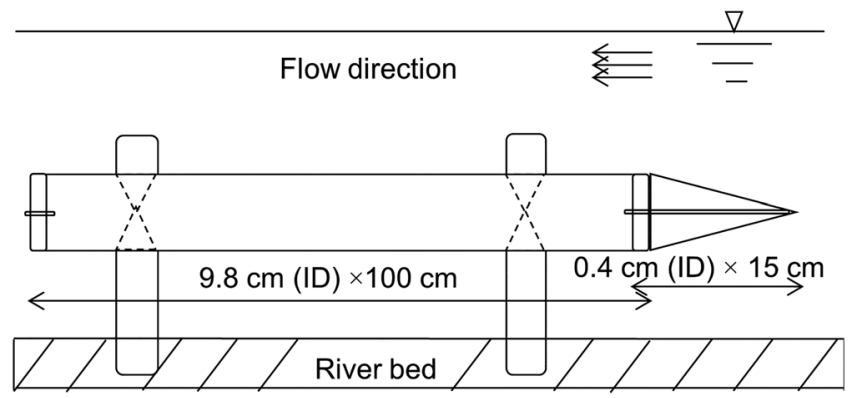

FIGURE 1 Side view of time-integrated fine sediment sampler (figure not to scale) outlet tube. Given the above characteristics, the TIFSS has the potential to provide an assessment of spatio-temporal sediment delivery processes as this cost-effective sampler can be installed at multiple locations within a hydrological network (e.g., Perks et al., 2017), including in remote settings and estuarine environments (Elliott et al., 2017).

The TIFSS has been extensively used to collect bulk samples of fine suspended sediment from a range of countries and environments, including Australia (Garzon-Garcia, Laceby, Olley, \& Bunn, 2017), Brazil (Le Gall et al., 2017), Canada (Smith \& Owens, 2014a), Finland (Gonzales-Inca et al., 2018), Japan (Yoshimura, Onda, Sakaguchi, Yamamoto, \& Matsuura, 2015), and the United Kingdom (Perks et al., 2017). Most published studies tend to focus on the utilization of this device for (a) the assessment of continuous sediment fluxes, (b) the properties of the transported sediment (e.g., particle size composition, contaminant, and nutrient content), and (c) identifying sediment sources in river studies. Researchers have also altered the original design of the Phillips et al. (2000) sampler (Table 1) to better suit their needs by changing the diameter of the inlet and/or outlet tube and the length and/or diameter of the main body (McDonald, Lamoureux, \& Warburton, 2010; McDowell \& Wilcock, 2007; Perks, Warburton, \& Bracken, 2014). Almost all of these modifications follow the basic principles of sedimentation and flow continuity within the sampler.

The hydrodynamic performance of the sampler and its mass collection efficiency (MCE) and particle size distribution (PSD) collection efficiency were first examined by Phillips et al. (2000) through a series of laboratory experiments. The influence of the existence of large composite particles on the PSD collection efficiency of the TIFSS under natural conditions, for rivers in the United Kingdom, was also discussed in the same paper. The effectiveness of the sampler, or its modified versions, to collect a representative sample of ambient fine sediment (regarding mass, PSD, and geochemical properties) has subsequently been investigated through several assessments. For example, Russell, Walling, and Hodgkinson (2000) evaluated the use of the sampler for characterizing a number of geochemical properties of the fine sediment load for several rivers in the United Kingdom. These authors concluded that the sampler statistically represented the ambient fine sediment in terms of its geochemical properties. McDonald et al. (2010) reported a study undertaken in Nunavut in the Canadian High Arctic with the river water velocity as high as $2.5 \mathrm{~m} \mathrm{~s}^{-1}$, aimed at assessing a modified sampler (i.e., Table 1) through

TABLE 1 Various modified versions of the time-integrated fine sediment sampler

\begin{tabular}{|c|c|c|c|c|}
\hline \multirow[b]{2}{*}{ Study } & \multirow{2}{*}{$\begin{array}{l}\text { Inlet tube } \\
\text { diameter } \\
(\mathrm{mm})\end{array}$} & \multicolumn{2}{|c|}{ Main chamber } & \multirow{2}{*}{$\begin{array}{l}\text { Outlet } \\
\text { diameter } \\
(\mathrm{mm})\end{array}$} \\
\hline & & $\begin{array}{l}\text { Diameter } \\
(\mathrm{mm})\end{array}$ & $\begin{array}{l}\text { Length } \\
(\mathrm{cm})\end{array}$ & \\
\hline $\begin{array}{l}\text { McDowell and Wilcock } \\
\text { (2007) }\end{array}$ & 2 & 48 & 100 & 2 \\
\hline McDonald et al. (2010) & 2 & 65 & 22.8 & 3 \\
\hline Perks et al. (2014) & 8 & 90 & 100 & 8 \\
\hline
\end{tabular}


another field evaluation. They (a) increased the ratio between the diameter of the main chamber and that of the inlet tube to enhance the MCE, (b) reduced the length of the main chamber from 1,000 to $228 \mathrm{~mm}$, and (c) placed a 3-mm (ID) outlet tube at the top of the end cap of the modified sampler, instead of the center, to suit the environment. In this case, and without further evaluation of the hydraulic performance of the modified sampler, application of the TIFSS did not accurately represent the ambient fine sediment concentration and its particle size composition. They argued that higher water velocities $\left(>1 \mathrm{~m} \mathrm{~s}^{-1}\right)$, shorter main chamber, and smaller inlet/outlet tube diameters may have significant effects on the poor performance of the modified version of TIFSS in terms of both MCE and PSD collection efficiency.

Subsequently, Perks et al. (2014) further validated the feasibility of using another modified version of the sampler to assess the fine sediment load of a river in the United Kingdom. The TIFSS was found to be inefficient in estimating the absolute fine sediment load, and the sampler underestimated the sediment mass flux between $66 \%$ and $99 \%$. However, a significant and constant relationship between samples collected over 2 years and the reference sediment load suggested that the mass of sediment collected by theTIFSS provided a relative measure of the sediment load. This supports the earlier finding of Schindler Wildhaber, Michel, Burkhardt-Holm, Bänninger, and Alewell (2012) for rivers in Switzerland. Perks et al. (2014) also reported statistically similar sediment properties between a number of samplers that were installed at the same river location within their research area. They used indirect approaches, such as the scaling factor and reverse stage-discharge relation methods, to convert the mass collected by the TIFSS samplers to the total sediment mass flux through river cross sections.

The most recent evaluation of the TIFSS was conducted by Smith and Owens (2014b). They assessed the maximum sediment MCE in a series of flume-based experiments. For two different kinds of sediment $\left(d_{50}=6.8 \mu \mathrm{m} ; \sigma=0.2 \mu \mathrm{m}\right.$ and $\left.d_{50}=99.5 \mu \mathrm{m} ; \sigma=0.2 \mu \mathrm{m}\right)$ and under an initial ambient suspended sediment concentration of $161 \mathrm{mg} \mathrm{L}^{-1}$, the MCEs of the TIFSS were determined to be $43 \%$ and $87 \%$, respectively. They argued that different MCEs for two different medium particle sizes reveal the fact that the MCE is dependent on the PSD of the ambient sediment. They also reported that the sampler collected sediment with representative PSDs during these experiments. However, field testing showed that sediment samples collected by the TIFSS had different concentrations for some metals when compared with nearby samples of fine-grained channel bed sediment in the Quesnel River, British Columbia, Canada, which could, in part, be due to the different time period over which samples were collected, in addition to differences in the particle size composition of the two types of sediment (i.e., bed and suspended).

To date, there has been little direct work to assess the mass and particle size collection efficiencies of the original TIFSS. In addition, the hydrodynamic behaviour of this device has not been rigorously characterized and validated since its inception. In recognition of the need to reassess the sampler, given its growing use within watersheds, the objective of this study was to re-examine the hydraulic characteristics, as well as the mass and particle size collection efficiencies, of the TIFSS.

\section{2 | SEMINAL PAPER REVIEW}

Flume tests were conducted in the laboratory by Phillips et al. (2000) to characterize the hydrodynamic behaviour of the sampler by establishing the relation between the flow velocities of the inlet tube and the ambient flow in the flume. Inlet tube flow velocities were estimated under different flume flow velocities over the range of 15.4 to $58.5 \mathrm{~cm} \mathrm{~s}^{-1}$. The inlet tube flow velocity during each flume flow velocity was estimated by measuring water velocity within a 7-mm (ID) glass tube that was placed over the inlet tube and by introducing air bubbles into the open end of the glass tube. The velocity within the glass tube was measured by observing how much time it took for the air bubble to pass along a 500-mm section of the glass tube. The mean flow velocity in the smaller inlet tube (i.e., $4 \mathrm{~mm}$ [ID]) was then estimated by

$$
y=1.75(x)
$$

where $y$ is the mean flow velocity in the 4-mm (ID) inlet tube $\left(\mathrm{cm} \mathrm{s}^{-1}\right)$, $x$ is the mean flow velocity in the 7-mm (ID) glass tube $\left(\mathrm{cm} \mathrm{s}^{-1}\right)$, and 1.75 was assumed as the cross-sectional area reduction ratio (or coefficient factor [CF]). The logarithmic regression fitting method was then used to demonstrate the close relation (i.e., coefficient of determination $\left[R^{2}\right]=0.99$ ) between measured flume flow velocities and estimated inlet tube velocities:

$$
k=2.074(z)-2.182
$$

where $k$ is the logarithmic inlet tube flow velocity and $z$ is the logarithmic flume flow velocity.

Using Equation (2), Phillips et al. (2000) reported that the inlet tube flow velocities were in the range of $12 \%$ to $53 \%$ of the flume flow velocity. Therefore, the authors assumed that (a) turbulent flow in the flume and frictional and inertial forces within the inlet tube were the primary factors causing the decrease in the inlet tube flow velocity relative to the flume flow velocity and (b) the TIFSS was not an isokinetic sampler, meaning that there was a risk of concentrating coarser particles $(>63 \mu \mathrm{m})$ in the sampler. However, they suggested that the oversampling for coarse sediments was less of an issue because fine suspended sediments were the dominant component of the sediment load in small first- and second-order lowland streams and because the $<63-\mu \mathrm{m}$ fraction is often the desired component for most applications (e.g., physical and geochemical properties, contaminant transport, and sediment fingerprinting).

The TIFSS efficiency in terms of the mass and PSD collection was assessed in the laboratory by introducing $1,000 \mathrm{mg} \mathrm{L}^{-1}$ of watersediment mixture into the sampler. In this step, two different chemically and ultrasonically dispersed PSDs of sediment $\left(d_{50}=3.3\right.$ and $10.2 \mu \mathrm{m}$ ) were emptied into buckets, and the sampler was connected to the base of the buckets. The inflowing discharges to the TIFSS were estimated as 0.025 and $0.242 \mathrm{~L} \mathrm{~min}^{-1}$ for each bucket so as to represent ambient flow velocities of 30 and $60 \mathrm{~cm} \mathrm{~s}^{-1}$ and inlet tube flow velocities of 3.3 and $32.1 \mathrm{~cm} \mathrm{~s}^{-1}$ (i.e., using Equation 2). The authors concluded that the sampler was effective in collecting fine suspended 
sediment across a range of flume flow velocities and across the whole particle size range evaluated, with MCEs between $31 \%$ and $71 \%$. The Kolmogorov-Smirnov test ( $\mathrm{K}-\mathrm{S}$ test) demonstrated that only under the low flume flow velocity $\left(30 \mathrm{~cm} \mathrm{~s}^{-1}\right)$ and coarser sediment conditions $\left(d_{50}=10.2 \mu \mathrm{m}\right)$ was the PSD of the collected sample statistically representative of the continuous inflowing sediment. However, they proposed that the mass collection and particle size efficiency of the TIFSS would be expected to increase under natural conditions probably due to the existence of aggregated particles or flocs.

The influence of sediment aggregation on the TIFSS efficiency was examined through field deployment. The sampler was installed in natural rivers in the United Kingdom, and suspended sediments were characterized by regularly collecting point samples of ambient sediment during the period of deployment. The authors highlighted two limitations to achieving a robust assessment of the TIFSS: (a) a lack of information to quantify the mass of continuous inflowing sediment (i.e., ambient and inlet tube flow velocity) and (b) difficulties in comparing the PSD of the TIFSS with the point samples of ambient suspended sediment. They were not able to overcome the first constraint; however, the concentration-weighted mean PSD of the point suspended sediment samples was calculated to determine the PSD collection efficiency of the sampler (for details, see Phillips et al., 2000). The authors stated that both the concentration-weighted and inlet tube flow velocity-weighted mean PSD calculations were required to obtain a fully representative sample entering the TIFSS. Nevertheless, as described previously, the lack of information on point ambient velocity was a major constraint to performing a thorough comparison between sediment collected by the TIFSS and the truly weighted mean PSD of continuous inflowing sediment (i.e., with reference to the ambient concentration and the inlet tube flow velocity).

Phillips et al. (2000) reported that time-integrated samples were statistically representative of the PSD under natural field conditions. They also suggested that the samples may be representative of the physical and geochemical properties of the ambient fine sediment. It is worth noting that the MCE of the TIFSS is limited by the effective PSD of ambient fine sediments and the residence time of such sediments within the main chamber. Therefore, Phillips et al. (2000) suggested that the TIFSS is suitable for collecting bulk representative samples rather than for estimating the time-integrated mass flux.

The determination of the MCE and PSD collection efficiency of the TIFSS in the laboratory experiments, described above, was dependent on the estimation of inlet tube flow velocity, which must accurately represent ambient flow velocity. There is still uncertainty in knowing the relationship between ambient and inlet tube flow velocities due to some issues. First, the simple air bubble method could be a source of error for estimating the inlet tube flow velocity, and this is discussed further later. Second, based on the mass conti-

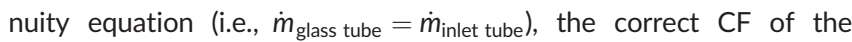
reduced cross-sectional area $(A)$ of the inlet tube should be 3.06 (i.e., $C F=\frac{A_{\text {glass tube }}}{A_{\text {inlet tube }}}=\left(\frac{7 \mathrm{~mm}}{4 \mathrm{~mm}}\right)^{2}$ ) and not 1.75 (Equation 1); the latter value is the ratio of the diameter of the glass tube over the inlet tube $\left(\frac{7 \mathrm{~mm}}{4 \mathrm{~mm}}\right)$. Third, by using the Phillips et al. (2000) logarithmic equation (i.e., Equation 2, considering 1.75 as the reduced crosssectional area coefficient), the inlet tube flow velocity at a flume flow velocity of $30 \mathrm{~cm} \mathrm{~s}^{-1}$ should be $7.6 \mathrm{~cm} \mathrm{~s}^{-1}$ and not $3.3 \mathrm{~cm} \mathrm{~s}^{-1}$.

These underestimations in the inlet tube flow velocities provide a longer residence time within the sampler and subsequently increase the MCE of the TIFSS. Therefore, the sediment mass and the measured PSD collection efficiencies (i.e., associated with the flume flow velocities of 30 and $60 \mathrm{~cm} \mathrm{~s}^{-1}$ ) in the original laboratory research are likely to be incorrect. Consequently, the maximum mass efficiencies presented in Smith and Owens (2014b) and other similar studies are uncertain because they also used Equation (2) to estimate inlet tube flow velocity. Further evaluation should, therefore, be conducted to address the issues just described.

Although the original laboratory assessments of the TIFSS acknowledged that there were some uncertainties (e.g., overestimating the mass and actual PSD collection efficiencies associated with the flume flow velocities of 30 and $60 \mathrm{~cm} \mathrm{~s}^{-1}$ ), it has been documented that the sampler provides useful spatio-temporal information of fine sediment transport and associated sediment properties, within watersheds. It is worth noting that the primary purpose of the original TIFSS was to obtain detailed information on the properties of the fine sediment transported in fluvial system by collecting a representative sample of ambient sediment rather than estimating the fine sediment mass flux within a river over time.

\section{I SAMPLER EVALUATION}

In the present study, the relation between the ambient and the inlet flow velocities was investigated in a laboratory flume using an acoustic Doppler velocimeter (ADV). In addition, the efficiency of the sampler in terms of the mass and PSD of the fine suspended sediment collected was assessed in a natural river (Red River, Manitoba, Canada). To obtain the MCE of the TIFSS in the field, (a) the ambient river flow velocity at the TIFSS location was measured using an acoustic Doppler current profiler (ADCP) during the period of deployment, (b) the mean inlet tube flow velocity was then estimated based on continuous river velocity measurement (i.e., using $\mathrm{ADCP}$ ) and using the empirical relation between ambient and inlet tube flow velocities obtained in the controlled laboratory conditions (i.e., using ADV), and (c) the mass of continuous inflowing sediment was calculated using point ambient $\mathrm{ADCP}$ velocity measurements and by collecting point river samples during the field evaluation using the following equation:

$$
\begin{aligned}
& M^{\prime}=A \times \sum_{j=1}^{n}\left(T_{j} \times V_{j} \times T S S_{j}\right) \\
& j=1, \quad 2, \quad \ldots, \quad n,
\end{aligned}
$$

where $M^{\prime}$ is the mass of continuous inflowing sediment (mg), $A$ is the internal inlet tube cross-sectional area $\left(0.126 \mathrm{~cm}^{2}\right), T_{j}$ is the time interval between two subsequent point samples $(\mathrm{s}), V_{j}$ and $T S S_{j}$ are the inlet tube flow velocity $\left(\mathrm{cm} \mathrm{s}^{-1}\right.$ ) and total suspended solids concentration ( $\mathrm{mg} \mathrm{cm}^{-3}$ ) associated with each time interval (i.e., $\frac{\partial T S S}{\partial T}$ or $\frac{\partial V}{\partial T} \neq 0$ ), j is the sample number, and $n$ is the total number of samples. The TSS 
concentration for each point sample (i.e., water-sediment bottle sample collected from the river) was obtained by filtering a well-mixed, measured volume of that sample through Whatman GF/F preweighed glass fibre filters $(0.7-\mu \mathrm{m}$ pore size) in the laboratory according to the ASTM Standard D3977-97 (2013).

Evaluation of the PSD collection efficiency of the sampler was based on the absolute PSD using a laser diffraction particle sizer (Malvern Mastersizer 2000, Malvern, UK). The absolute PSD for each point sample and sediment collected by the sampler was obtained after performing standard pretreatment procedure including using hydrogen peroxide to remove organic matter and adding a $0.4 \%$ solution of sodium hexametaphosphate to disperse and homogenize inorganic sediment samples (see Phillips et al., 2000 for more details). Given the ADCP velocity measurements and the TSS concentration values at each time interval throughout the study period, the velocity-weighted and concentration-weighted mean PSD of the point suspended sediment samples was calculated using

$$
\begin{aligned}
& D_{i}=\frac{\sum_{j=1}^{n}\left(\left(d_{i}\right)_{j} \times V_{j} \times T S S_{j}\right)}{\sum_{j=1}^{n}\left(V_{j} \times T S S_{j}\right)} \\
& j=1, \quad 2, \ldots, \quad n,
\end{aligned}
$$

where $D_{i}$ and $d_{i}$ are the diameter that $i \%$ of particles are smaller in weighted mean PSD and point samples, respectively.

\section{1 | Hydrodynamic characteristics: Laboratory evaluation}

\subsection{1 | Experimental set-up and measurement procedure}

The laboratory experiments were conducted in a rectangular flume in the Hydraulics Research and Testing Facility at the University of Manitoba, Canada. The flume was $13.1 \mathrm{~m}$ long, $0.95 \mathrm{~m}$ wide, and $0.71 \mathrm{~m}$ deep and had a bed slope of $0.0056\left(\mathrm{~m} \mathrm{~m}^{-1}\right)$. The flume bed was sheet metal, and the walls were glass. A flow straightener consisting of several rows of polyvinylchloride pipes $(0.14 \mathrm{~m}$ diameter, $0.25 \mathrm{~m}$ long) surrounded by two wire mesh screens was located in the upstream head tank to filter the flow. A louvered tailgate manually controlled water level at the downstream end of the flume and discharge was measured by an ultrasonic flow metre. In this study, the flume discharges were controlled in a way that average flume flow velocities are similar to those of Phillips et al. (2000) i.e., five velocities in the range 15 to $60 \mathrm{~cm} \mathrm{~s}^{-1}$ ).

A down-looking Vectrino II profiling ADV (Nortek, Rud, Norway) was used to measure inlet tube flow velocity. The ADV was mounted on a frame over the flume (Figure 2), so it could be moved in the vertical direction and along the centreline of the flume. Prior to conducting the experiments, the ADV probe was aligned in the streamwise and vertical directions using a small level, and an initial experiment was undertaken to determine the length of flume required for the flow to be fully developed. Under the minimum flow velocity of the flume (i.e., $15 \mathrm{~cm} \mathrm{~s}^{-1}$ ), the flow became fully developed at

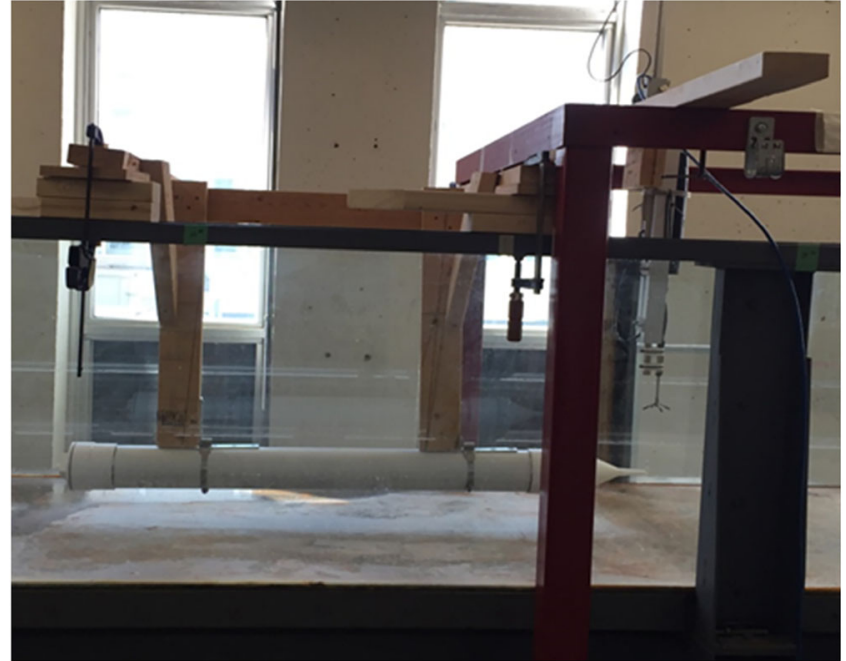

FIGURE 2 The time-integrated fine sediment sampler and acoustic Doppler velocimeter used to determine the inlet tube flow velocity in the laboratory-based evaluation

$7 \mathrm{~m}$ downstream of the flume inlet; therefore, the TIFSS was located at $9 \mathrm{~m}$ from the flume inlet. For all tests, the water level was maintained constant at $30 \mathrm{~cm}$, and the TIFSS was installed at the centreline of the flume, and in this condition, the distance between the inlet tube of the TIFSS and the flume bed was $14.5 \mathrm{~cm}$ (i.e., $~ 50 \%$ of the water depth). As designed by the manufacturer, the centre of the sampling volume of the ADV was located $5 \mathrm{~cm}$ below the sensors to avoid any disturbance of the flow structure at the focus point of the transmitter.

Preliminarily tests were conducted to determine an appropriate closest horizontal distance of the ADV from the TIFSS inlet tube. Hence, the ADV collected velocity data for $20 \mathrm{~min}$ at different horizontal distances of $0,5,10,15$, and $20 \mathrm{~mm}$ to the sampler inlet tube. Analysis of the data indicated that $5 \mathrm{~mm}$ was the smallest distance that the ADV could record long-term accurate velocity measurements. As all of the flows associated with the five velocities were subcritical (i.e., Froude number less than unity), it is reasonable to assume that flow conditions were controlled from downstream. In other words, flow conditions including the frictional drag forces associated with the inlet tube walls or internal controls on velocity within the inlet tube of the TIFSS were transmitted upstream. Thus, it can be assumed that the flume flow velocity measurements acquired $5 \mathrm{~mm}$ upstream of the inlet tube were representative of the velocities within the inlet tube.

To measure the flow velocity profile in front of the sampler, the ADV sampling volume was placed at three locations: one directly in front of the TIFSS inlet tube, one $7 \mathrm{~mm}$ vertically above, and one $7 \mathrm{~mm}$ below the sampler. For each of the measurement locations, the flow velocity was recorded for $20 \mathrm{~min}$ at a frequency of $100 \mathrm{~Hz}$. The ADV sampling volume was divided into seven separate cells of 1-mm height where water velocity was simultaneously measured, which resulted in a total of 21 water velocity measurement points in front of the sampler inlet. After the measurements in the laboratory, a post-processing code in MATLAB was utilized to filter the data set 
based on the correlation and signal-to-noise ratio values. In each cell, if more than $10 \%$ of measured data had a correlation below $30 \%$ or had a signal-to-noise ratio value less than $15 \mathrm{~dB}$, the cell was eliminated.

\subsection{2 | Laboratory data analysis}

The velocity profile distributions in front of the TIFSS show that for each run (i.e., different flume flow velocities), the minimum velocity occurred at the inlet tube and increased away from the centreline of the sampler (Figure 3). The results of the relation between the measured inlet tube flow velocities (i.e., ADV velocity profile measurements) and flume flow velocities in the range $15-60 \mathrm{~cm} \mathrm{~s}^{-1}$ are presented in Figure 4, which demonstrates a strong, statistically significant linear relationship. Figure 4 also illustrates the relation between the measured flume flow velocities and inlet tube flow velocity estimations associated with (a) the original development by Phillips et al. (2000; i.e., using the diameter of the glass tube over the inlet tube $\left(\frac{7 \mathrm{~mm}}{4 \mathrm{~mm}}\right)$ as the reduced cross-sectional area coefficient; Equation 2) and (b) the air bubble method (i.e., Phillips et al., 2000 procedure) with the correct cross-sectional area reduction ratio (i.e., $\left(\frac{7 \mathrm{~mm}}{4 \mathrm{~mm}}\right)^{2}$ ). Figure 4 demonstrates that estimated inlet tube flow velocities with the correct $\mathrm{CF}$ for the reduction ratio (i.e., 3.06) at $60 \mathrm{~cm} \mathrm{~s}^{-1}$ of flume flow velocity are in agreement with the ADV inlet tube flow velocity measurements. It can also be seen that the percentage differences between the flume flow and estimated inlet tube flow velocities with the correct CF at five flume flow velocities are not consistent and this percentage increases as the flume flow velocity decreased (e.g., $78 \%$ and $6 \%$ at flume flow velocities of 15 and $60 \mathrm{~cm} \mathrm{~s}^{-1}$, respectively). Possible explanation for this inconsistency is that at lower flume flow velocities, the frictional and inertial forces within the 600-mm glass tube exerted additional limitation on the inlet tube flow velocity. Moreover, Phillips et al. (2000) observed (i.e., by introducing an air bubble) that developing turbulent flow at higher flume flow velocities (i.e., $>60 \mathrm{~cm} \mathrm{~s}^{-1}$ ) caused significant decreases in the inlet flow velocity. Therefore, it is most likely that the air bubble method for estimating inlet tube flow velocity may not be a precise method for whole desired range of flume velocities and could be a source of error. It can also be seen that for developing a regression, logarithmic transformation of the flume flow velocities and inlet tube flow velocities is not required.

The results of the laboratory test of the hydrodynamic characteristics of the sampler (Figure 4) highlight the marked increases in the measured inlet tube flow velocities compared with the original estimated inlet flow velocities (i.e., air bubble method; $C F=1.75$ ). The inlet tube flow velocities at flume flow velocities of 60 and $30 \mathrm{~cm} \mathrm{~s}$ ${ }^{-1}$, for example, were measured (i.e., using the ADV) to be 52 and $24 \mathrm{~cm} \mathrm{~s}^{-1}$, respectively, and were estimated (i.e., by Phillips et al., 2000) to be 32.1 and $3.3 \mathrm{~cm} \mathrm{~s}^{-1}$, respectively. Therefore, the MCEs of the TIFSS in the original laboratory tests by Phillips et al. (2000) were influenced by underestimations of the inlet tube flow velocities.
FIGURE 3 Velocity profiles in front of the time-integrated fine sediment sampler for various flume discharges
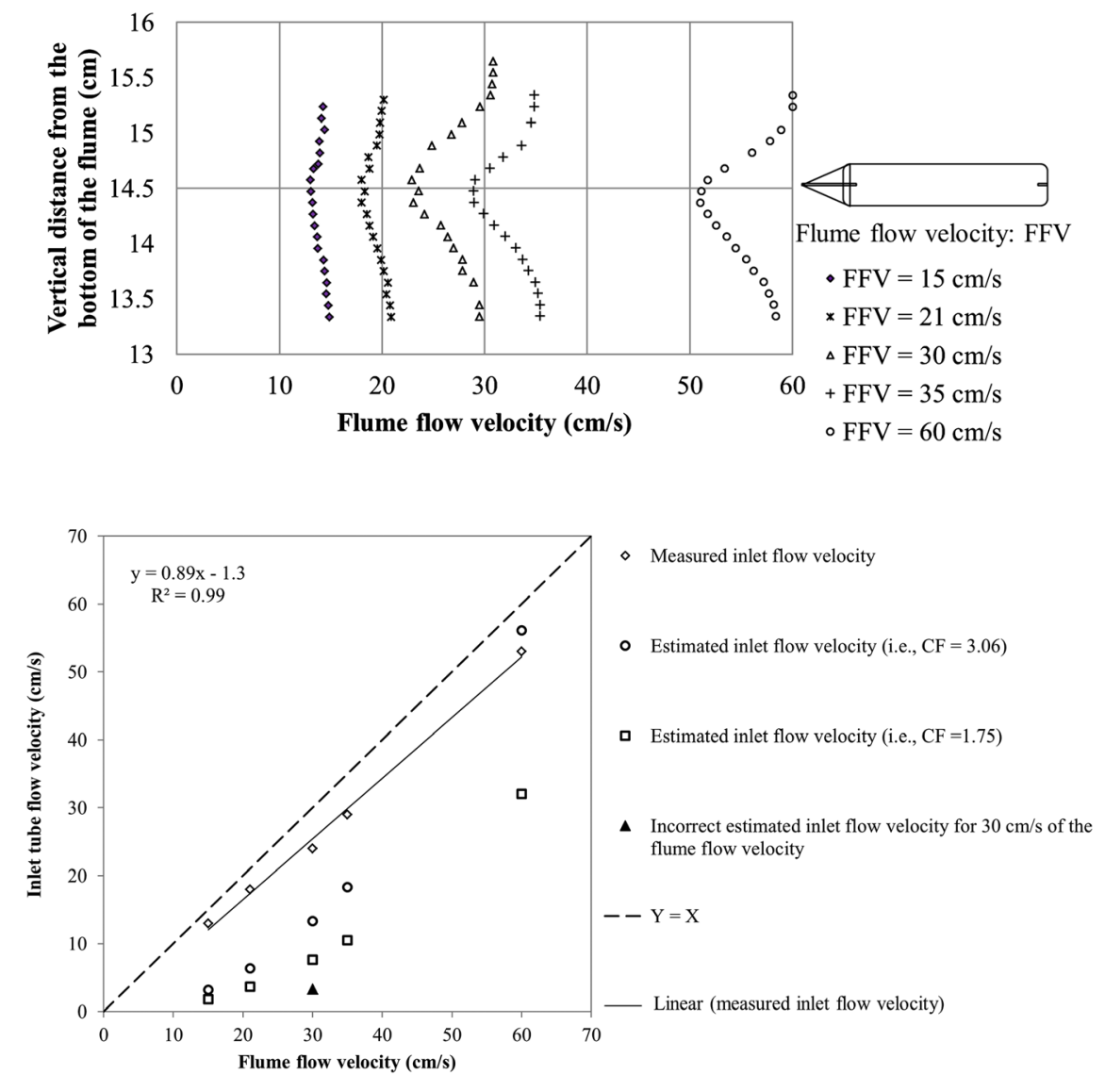

FIGURE 4 Linear relationship between ambient flume flow, measured inlet, and estimated inlet tube flow velocities. CF, coefficient factor 
Despite these uncertainties associated with the MCEs in the original laboratory assessment, three points are worthy of attention regarding the performance of the TIFSS. First, the original purpose of the design and development of the TIFSS was to collect a representative sample of substantial mass (e.g., $>10 \mathrm{~g}$ ) rather than estimating the continuous fine sediment mass flux. Second, and closely related to the first point, the two previous studies, which assessed the use of the original TIFSS (i.e., not its modified versions) for collecting fine sediments in natural river systems (i.e., Phillips et al., 2000; Smith \& Owens, 2014b), show that the sampler collects a representative sample of ambient fine suspended sediment. Third, the ADV velocity measurements (i.e., Figure 4) confirmed that the ratio of the inlet tube flow velocity to the flume flow velocity (i.e., inflow efficiency) within the range $15-60 \mathrm{~cm} \mathrm{~s}^{-1}$ was $87 \% \pm 2 \%$ (mean \pm one standard error), which means that the TIFSS can be considered as an isokinetic sampler because this ratio is in the acceptable range of $1.00 \pm 0.15$ (Szalona, 1982). In relating the TIFSS inflow efficiency (i.e., 87\%), it can be also assumed that a representative sample of fine suspended sediment in ambient water (in terms of concentration and PSD) enters into the sampler (Garcia, 2008). Given the fact that a major, if not the dominant, part of the fine-grained sediment load transported in many rivers is composed of aggregates and flocculated particles (Droppo, 2001), the TIFSS collects a sufficient mass of such particles according to the basic principles of sedimentation (i.e., settling velocity). As a result, it is unlikely that the issues raised above will influence the functionality of the TIFSS for the collection of a representative sample of suspended sediment under most field conditions.

\section{2 | Field evaluation}

After obtaining the empirical relation between ambient and inlet tube flow velocities (i.e., Figure 4), the TIFSS was attached to a frame and installed approximately $5 \mathrm{~m}$ from a riverbank in the Red River in Winnipeg, Manitoba, Canada (14 U, 634498E, and 5518722N) for 3 days in November 2016. This short duration and one-time field sampling were performed to provide additional insight into the ability of the sampler to collect representative samples as well as to evaluate a novel approach for measuring its MCE in the field. The Red River is a wide, open channel (Goharrokhi, 2015), and its suspended sediment load is mainly composed of clay- and silt-sized particles (Kimiaghalam, Goharrokhi, \& Clark, 2016). Some of the primary characteristics of the Red River during the ice-free period are reported in Table 2 (Goharrokhi, 2015; Kimiaghalam et al., 2016).

A local water level recorder was installed upstream of the sampler prior to the beginning of the project, which measured water level every $15 \mathrm{~min}$. Continuous water level monitoring was used to observe potential hourly and daily stage variations. Continuous point velocity measurements were obtained for $1 \mathrm{hr}$ at a frequency of $1 \mathrm{~Hz}$ using an ADCP RiverSurveyor M9 (SonTek, San Diego, USA) that was mounted on the TIFSS frame. In addition, 1-L bottle and 7-L bucket point samples were collected every $6 \mathrm{hr}$ at the TIFSS location to (a) capture the variation of TSS concentrations using
TABLE 2 Primary properties of the Red River, Manitoba, Canada, during the ice-free period

\begin{tabular}{lccc} 
Property & Maximum & Minimum & Average \\
\hline Bed gradient $\left(\mathrm{m} \mathrm{km}^{-1}\right)$ & - & - & 0.04 \\
\hline Water surface elevation $(\mathrm{m})$ & 229.0 & 222.5 & 223.6 \\
\hline Top width $(\mathrm{m})^{*}$ & 159 & 115 & 130 \\
\hline Thalweg depth $(\mathrm{m})^{*}$ & 10.5 & 4.5 & 5.5 \\
\hline Hydraulic radius $(\mathrm{m})^{*}$ & 7.0 & 2.5 & 3.9 \\
\hline Velocity $\left(\mathrm{m} \mathrm{s}^{-1}\right)^{*}$ & 1.08 & 0.10 & 0.64 \\
\hline Discharge $\left(\mathrm{m}^{3} \mathrm{~s}^{-1}\right)$ & 1,300 & 50 & 176 \\
\hline Suspended sediment & 1,500 & 10 & 121 \\
\hline concentration $\left(\mathrm{mg} \mathrm{L}^{-1}\right)$ & & & \\
\hline
\end{tabular}

*At a monitoring site located $4 \mathrm{~km}$ upstream of the time-integrated fine sediment sampler location.

the water bottle samples, (b) perform PSD analysis after collecting sediments from the 7-L water-sediment mixture bucket samples by allowing sediments to settle for 7 days (described later), (c) calculate the weighted mean PSD for the point samples, and (d) assess the PSD collection efficiency of the sampler. The TIFSS was retrieved after 3 days, and the collected sample was emptied into a 20-L bucket. After 7 days, the clear supernatant water of the 20- and 7 $\mathrm{L}$ buckets was carefully siphoned, and the settled sediments were then air dried and retained for subsequent analyses (for details, see Perks et al., 2014).

The total mass of sediment collected by the TIFSS after $72 \mathrm{hr}$ was $4.7 \mathrm{~g}$, which is a sufficient mass for a broad spectrum of analyses including geochemical content, particle size composition, organic matter/carbon content, and colour properties for sediment fingerprinting. The ADCP velocity measurements indicate that the mean river velocity for the 3 -day period and at the TIFSS location was $15 \pm 2.1 \mathrm{~cm} \mathrm{~s}^{-1}$ and accordingly, the mean inlet tube flow velocity was calculated as $13 \mathrm{~cm} \mathrm{~s}^{-1}$ (see Figure 4; inlet tube flow velocity $\left(\mathrm{cm} \mathrm{s}^{-1}\right)=\left(0.89 \times\right.$ ambient flow velocity $\left.\left.\left(\mathrm{cm} \mathrm{s}^{-1}\right)-1.3\right)\right)$. In the Red River, the water surface elevation between bank-full and low flow conditions typically varies by up to $7 \mathrm{~m}$ (Table 2); however, the variation of the water surface elevation for the entire period (i.e., 3 days) was less than $10 \mathrm{~cm}$. Therefore, the flow regime during the study period was approximately steady state, the velocity distribution at the TIFSS location did not change significantly, and, thus, the mean ADCP velocity measurement over $1 \mathrm{hr}$ and the mean inlet tube flow velocity associated with that (i.e., 15 and $13 \mathrm{~cm} \mathrm{~s}^{-1}$, respectively) can be considered representative of the period of field deployment. The average TSS concentration value was $143 \pm 13.5 \mathrm{mg} \mathrm{L}^{-1}$. Given the internal inlet tube cross-sectional area (i.e., $0.126 \mathrm{~cm}^{2}$ ) of the TIFSS, the ADCP velocity measurements, and the TSS concentration values at each time interval throughout the study period, the inflowing sediment mass to the sampler was calculated as $60 \mathrm{~g}$ (i.e., using Equation 3), and subsequently, the MCE of the sampler was estimated to be $8 \%$. This low measured MCE is consistent with estimations by Perks et al. (2014) that indicates that this device may not be suitable for estimating absolute sediment load, a conclusion that is broadly 


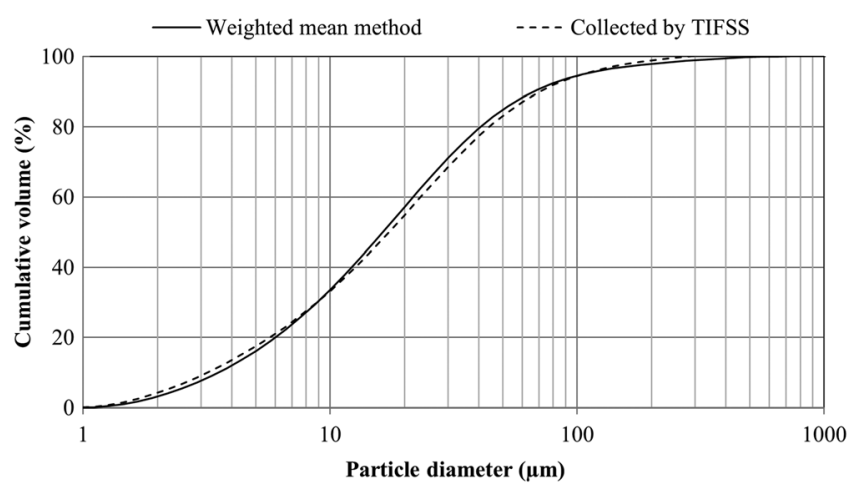

FIGURE 5 Volumetric particle size distribution of the inlet tube flow velocity- and concentration-weighted mean method and the sediment collected by the time-integrated fine sediment sampler (TIFSS)

supportive of the findings of other evaluations (e.g., Phillips et al., 2000; Schindler Wildhaber et al., 2012).

The weighted mean PSD for point suspended sediment samples (i.e., concentration and inlet tube flow velocity weighted) was obtained using Equation (4). The K-S test was applied on the PSD of the time-integrated sample and the weighted mean PSD (see Phillips et al., 2000 for more details). The similarity of the PSD shown in Figure 5 and the $\mathrm{K}-\mathrm{S}$ test result ( 0.025 at $95 \%$ confidence level) indicate that the PSD of the suspended sediment collected by the TIFSS is statistically representative of the suspended sediment load of the Red River at the time of deployment.

\section{4 | CONCLUSIONS}

The TIFSS is a well-established and reliable sampler for collecting a representative sample (i.e., in terms of PSD and geochemical properties) from small first- and second-order lowland streams over extended periods. However, there are two issues of concern associated with the laboratory evaluations of the TIFSS in the original paper by Phillips et al. (2000). First is the incorrect cross-sectional area reduction coefficient (i.e., 1.75) that results in an underestimation of the inlet tube flow velocity. Second, and consequently, under the original development of the TIFSS (i.e., using chemically and ultrasonically dispersed fine sediment), the MCEs of the sampler were overestimated. This paper re-examined the performance of the TIFSS using different measurement methods and characterized the potential influences of the issues raised above on the functionality of the sampler. Results from ADV measurements in controlled laboratory conditions demonstrated that the original equation between the ambient and inlet tube flow velocities should be modified. In addition, an ADCP was used to determine the mass of continuous inflowing sediment under field conditions and to calculate the concentration- and velocity-weighted mean PSD of the time-integrated sediment entering the sampler. The findings of laboratory experiments indicated that the real inlet tube flow velocity of the TIFSS is significantly higher than previously reported (up to 7.3 times), and in turn, the sampler provides less travel time for the composite particles inside the main chamber, resulting in lower MCE than previously assumed. In contrast with the laboratory findings in Phillips et al. (2000), the ADV measurements illustrated that the TIFSS inflow efficiency was $87 \%$. Therefore, it can be assumed that throughout the sampler's operating velocity, a representative sample of the fine particles of the ambient water enters into the sampler. Field deployment of the TIFSS indicated that the sampler collected a representative sample of fine suspended sediment in terms of PSD that may reflect both the isokinetic behaviour of the sampler and the existence of aggregated particles or flocs as a dominant natural state of fine cohesive materials in river systems. The MCE of the sampler in the field was measured to be as low as $\sim 10 \%$. The results of the field trails support previous studies that found that although the TIFSS collects a statistically representative sample of ambient suspended sediment, care must be exercised when considering the mass of the sediment collected by the sampler as an indicator for estimating the absolute time-integrated mass flux of sediment during the period of field deployment. Given the fact that a large proportion of the suspended sediment flux probably occurs during high run-off events and flood flows, which in natural rivers may be greater than $60 \mathrm{~cm} \mathrm{~s}^{-1}$, it is recommended that future work should examine the effect of higher flow velocities on the performance of the TIFSS.

\section{ACKNOWLEDGMENTS}

This research was supported by the Natural Science and Engineering Research Council of Canada (NSERC) CREATE H2O, CRD BaySys, and Discovery (DAL) grant programmes. The authors would like to thank Brendan Brooks and Alexander Wall for their help with the field and laboratory work.

\section{ORCID}

Masoud Goharrokhi (D) https://orcid.org/0000-0003-4172-0242

\section{REFERENCES}

ASTM Standard D3977-97 (2013). Standard test methods for determining sediment concentration in water samples. West Conshohocken, PA, USA: ASTM International.

Droppo, I. G. (2001). Rethinking what constitutes suspended sediment. Hydrological Processes, 15, 1551-1564. https://doi.org/10.1002/ hyp.228

Elliott, E. A., Monbureau, E., Walters, G. W., Elliott, M. A., McKee, B. A., \& Rodriguez, A. B. (2017). A novel method for sampling the suspended sediment load in the tidal environment using bi-directional timeintegrated mass-flux sediment (TIMS) samplers. Estuarine, Coastal and Shelf Science, 199, 14-24. https://doi.org/10.1016/j.ecss.2017.08.029

Foster, I. D. L., \& Lees, J. A. (1999). Changes in the physical and geochemical properties of suspended sediment delivered to the headwaters of LOIS river basins over the last 100 years: A preliminary analysis of lake and reservoir bottom sediment. Hydrological Processes, 13, 1067-1086. https://doi.org/10.1002/(SICI)1099-1085(199905)13:7<1067::AID HYP790>3.0.CO;2-Y

Garcia, M. H. (2008). ASCE manual of practice 110-Sedimentation engineering: Processes, measurements, modeling and practice. In World Environmental and Water Resource Congress 2006: Examining the confluence of environmental and water concerns (p. 1050). New York: ASCE. ISSN 0734-7685. https://doi.org/10.1061/9780784408148 
Garzon-Garcia, A., Laceby, J. P., Olley, J. M., \& Bunn, S. E. (2017). Differentiating the sources of fine sediment, organic matter and nitrogen in a subtropical Australian catchment. Science of the Total Environment, 575, 1384-1394. https://doi.org/10.1016/j.scitotenv.2016.09.219

Goharrokhi, M. (2015). Effect of hydraulic shear stress on the banks of the Red River. Unpublished MSC Thesis, University of Manitoba, Winnipeg, Canada.

Gonzales-Inca, C., Valkama, P., Lill, J. O., Slotte, J., Hietaharju, E., \& Uusitalo, R. (2018). Spatial modeling of sediment transfer and identification of sediment sources during snowmelt in an agricultural watershed in boreal climate. Science of the Total Environment, 612, 303-312. https://doi.org/10.1016/j.scitotenv.2017.08.142

Kimiaghalam, N., Goharrokhi, M., \& Clark, S. P. (2016). Assessment of wide river characteristics using an acoustic Doppler current profiler. Journal of Hydrologic Engineering, 21, 06016012. https://doi.org/10.1061/ (ASCE)HE.1943-5584.0001447

Kondolf, G. M., Schmitt, R. J., Carling, P., Darby, S., Arias, M., Bizzi, S., ... Oeurng, C. (2018). Changing sediment budget of the Mekong: Cumulative threats and management strategies for a large river basin. Science of the Total Environment, 625, 114-134. https://doi.org/10.1016/j. scitotenv.2017.11.361

Le Gall, M., Evrard, O., Dapoigny, A., Tiecher, T., Zafar, M., Minella, J. P. G., ... Ayrault, S. (2017). Tracing sediment sources in a subtropical agricultural catchment of Southern Brazil cultivated with conventional and conservation farming practices. Land Degradation \& Development, 28 , 1426-1436. https://doi.org/10.1002/ldr.2662

McDonald, D. M., Lamoureux, S. F., \& Warburton, J. (2010). Assessment of a time-integrated fluvial suspended sediment sampler in a high arctic setting. Geografiska Annaler: Series A, Physical Geography, 92, 225-235. https://doi.org/10.1111/j.1468-0459.2010.00391.x

McDowell, R. W., \& Wilcock, R. J. (2007). Sources of sediment and phosphorus in stream flow of a highly productive dairy farmed catchment. Journal of Environmental Quality, 36, 540-548. https://doi.org/ 10.2134/jeq2006.0352

Owens, P. N., Batalla, R. J., Collins, A. J., Gomez, B., Hicks, D. M., Horowitz, A. J., ... Trustrum, N. A. (2005). Fine-grained sediment in river systems: Environmental significance and management issues. River Research and Applications, 21, 693-717. https://doi.org/10.1002/rra.878

Owens, P. N., Blake, W. H., Gaspar, L., Gateuille, D., Koiter, A. J., Lobb, D. A., ... Woodward, J. C. (2016). Fingerprinting and tracing the sources of soils and sediments: Earth and ocean science, geoarchaeological, forensic, and human health applications. Earth-Science Reviews, 162, 1-23. https://doi.org/10.1016/j.earscirev.2016.08.012

Perks, M. T., Warburton, J., \& Bracken, L. (2014). Critical assessment and validation of a time-integrating fluvial suspended sediment sampler. Hydrological Processes, 28, 4795-4807. https://doi.org/10.1002/ hyp.9985

Perks, M. T., Warburton, J., Bracken, L. J., Reaney, S. M., Emery, S. B., \& Hirst, S. (2017). Use of spatially distributed time-integrated sediment sampling networks and distributed fine sediment modelling to inform catchment management. Journal of Environmental Management, 202, 469-478. https://doi.org/10.1016/j.jenvman.2017.01.045

Phillips, J. M., Russell, M. A., \& Walling, D. E. (2000). Time-integrated sampling of fluvial suspended sediment: A simple methodology for small catchments. Hydrological Processes, 14, 2589-2602. https://doi. org/10.1002/1099-1085(20001015)14:14<2589::AID-HYP94>3.0. CO;2-D

Russell, M. A., Walling, D. E., \& Hodgkinson, R. A. (2000). Appraisal of a simple sampling device for collecting time-integrated fluvial suspended sediment samples. In The role of erosion and sediment transport in nutrient and contaminant transfer. IAHS Publication No. 263. (pp. 119-127). Wallingford: IAHS Press.

Schindler Wildhaber, Y., Michel, C., Burkhardt-Holm, P., Bänninger, D., \& Alewell, C. (2012). Measurement of spatial and temporal fine sediment dynamics in a small river. Hydrology and Earth System Sciences, 16, 1501-1515. https://doi.org/10.5194/hess-16-1501-2012

Smith, T. B., \& Owens, P. N. (2014a). Individual and cumulative effects of agriculture, forestry and metal mining activities on the metal and phosphorus content of fine-grained sediment; Quesnel River basin, British Columbia, Canada. Science of the Total Environment, 496, 435-442. https://doi.org/10.1016/j.scitotenv.2014.07.014

Smith, T. B., \& Owens, P. N. (2014b). Flume-and field-based evaluation of a time-integrated suspended sediment sampler for the analysis of sediment properties. Earth Surface Processes and Landforms, 39, 1197-1207. https://doi.org/10.1002/esp.3528

Szalona, J.J., 1982. Development of a bag-type suspended-sediment sampler/A study of methods used in measurement and analysis of sediment loads in streams, Report Y: Minneapolis, Minnesota, Federal Inter-Agency Sedimentation Project, St. Anthony Falls Hydraulic Laboratory, $32 \mathrm{p}$

Walling, D. E. (2013). The evolution of sediment source fingerprinting investigations in fluvial systems. Journal of Soils and Sediments, 13, 1658-1675. https://doi.org/10.1007/s11368-013-0767-2

Walling, D. E., Owens, P. N., Waterfall, B. D., Leeks, G. J., \& Wass, P. D. (2000). The particle size characteristics of fluvial suspended sediment in the Humber and Tweed catchments, UK. Science of the Total Environment, 251, 205-222. https://doi.org/10.1016/s00489697(00)00384-3

Yoshimura, K., Onda, Y., Sakaguchi, A., Yamamoto, M., \& Matsuura, Y. (2015). An extensive study of the concentrations of particulate/dissolved radiocaesium derived from the Fukushima Daiichi Nuclear Power Plant accident in various river systems and their relationship with catchment inventory. Journal of Environmental Radioactivity, 139, 370-378. https://doi.org/10.1016/j.jenvrad.2014.08.021

How to cite this article: Goharrokhi M, Pahlavan H, Lobb DA, Owens PN, Clark SP. Assessing issues associated with a timeintegrated fluvial fine sediment sampler. Hydrological Processes. 2019;33:2048-2056. https://doi.org/10.1002/hyp.13451 